\title{
Takotsubo Kardiyomyopatili Acil Hastada Anestezik Yaklaşım
}

\author{
Sedat Hakimoğlu*, Onur Koyuncu, Sümeyra Yeșil
}

DOI: $10.17944 /$ mkutfd.408830

Sedat Hakimoğlu: Doç. Dr., Hatay Mustafa Kemal Üniversitesi Tıp Fakültesi Anesteziyoloji ve Reanimasyon Anabilim Dalı, Hatay Email: sedathakimoglu@gmail.com ORCID iD: https://orcid.org/0000-0002-1556-7996

Onur Koyuncu: Doç. Dr., Hatay Mustafa Kemal Üniversitesi Tıp Fakültesi Anesteziyoloji ve Reanimasyon Anabilim Dalı, Hatay

Email: onurko@yahoo.com

ORCID iD: https://orcid.org/0000-0002-0282-181X

Sümeyra Yeșil: Arș. Gör. Dr., Hatay Mustafa Kemal Üniversitesi Tıp Fakültesi Anesteziyoloji ve Reanimasyon Anabilim Dalı, Hatay

Email: sumeyray86@gmail.com

ORCID iD: https://orcid.org/0000-0002-7029-5946

Bildirimler/Acknowledgement

* Sorumlu Yazar/Corresponding Author

Çıkar Çatıșması/Conflict of Interest Yazarlar bu makale ile ilgili herhangi bir çıkar catıșması bildirmemișlerdir.

The authors declare that they have no conflict of interests regarding content of this article.

Maddi Destek/Financial Support

Yazarlar bu makale ile ilgili herhangi bir finansal destek bildirmemișlerdir.

The Authors report no financial support regarding content of this article.

\section{Etik Beyan/Ethical Declaration}

Yazarlar, çalıșmanın yürütülmesi esnasında Helsink Beyannamesi 2013, ICJM tavsiyeleri ile COPE'un Editör ve Yazarlar için Uluslararası Standartlarının yanısıra ilgili diğer biyoetik kılavuzların dikkate alındığını beyan etmișlerdir.

Geliș/Received: 23.03.2018

Kabul/Accepted: 15.01.2020

e-ISSN: 2149-3103

Web: http://dergipark.org.tr/mkutfd
Öz

Takotsubo Kardiyomyopatili Acil Hastada Anestezik Yaklașım

Takatsubo kardiyomiyopatisi (1) (TKM), sıkıkla postmenapozal kadınlarda görülen, akut stres sonrasında katekolamin deşarjina veya koroner arter spazmına bağlı gelișen, akut myokard infarktüsüne benzer bir tablodur. TKM genellikle geri dönüșümlü sol ventrikül yetmezliği ile karakterizedir ve șüpheli akut koroner sendromların \%1-3'ünü olușturur. En sık semptomlar göğüs ağrısı, senkop, dispnedir ve anormal ST ve T (-) değișiklikleri EKG' de sıklkkla görülür. Bu olgu sunumunda TKM'li acil sezeryan seksiyo nedeniyle operasyonuna alınmıș 19 yașında gebedeki anestezi yaklașımımız sunulmuștur.

Anahtar Kelimeler: Takotsubo, kardiyomiyopati, anestezi

\section{Abstract}

Anesthetic Approach to Emergency Patient with Takotsubo Cardiomyopathy

Takatsubo cardiomyopathy (TKM) is a table similar to the acute myocardial infarction seen in postmenopausal women, which is catecholamine discharge due to acute stress or coronary artery spasm. TKM is usually characterized by recurrent left ventricular failure and constitutes 1-3\% of suspected acute coronary syndromes. The most common symptoms are chest pain, syncope, dyspnea and abnormal ST and T (-) changes are frequently seen in ECG. In this case report, our anesthesia approach is presented in a 19-year-old pregnant with TKM who was operated on because of urgent cesarean section.

Keywords: Takotsubo, cardiomyopathy, anesthesia

\section{GİRİ̧}

Takatsubo kardiyomiyopatisi (TKM), Amerikan Kalp Cemiyeti tarafından kardiyomiyopatiler içerisinde sınıflandırılmaktadır. 1990 yılından önce bu hastalıktan yayınlarda farklı teminolojilerle bahsedilmiş olsa da Japonya'dan Sato ve ark. TKM terimini ilk kez tanımlamıșlardır. Hastalık ismini Japonya'da ahtapot yakalamakta kullanılan bir çeşit çömleğe benzemesi nedeniyle almıștır $(1,2)$. Literatürde "Stresle İlişkili Kardiyomiyopati, Geçici Sol Ventrikül Apikal Balonlaşma Sendromu, Ampulla Kardiyomiyopatisi, Kırık Kalp Sendromu" olarak da isimlendirilmektedir.

Şüpheli akut koroner sendromların \%1-3'ünü oluşturur ve geri dönüşümlü sol ventrikül akinezisi ile karakterizedir. Sıklıkla postmenopozal kadınlarda görülür (3). Sıklıkla postmenapozal kadınlarda, akut stres sonrasında katekolamin deşarjı veya koroner arter spazmına bağlı gelişmektedir. Reverse Takotsubo, sağ ventrikül Takotsubo ve global hipokinezi gibi nadir formları da bulunmaktadır $(4,5)$. Hastalarda en sık görülen semptomlar; göğüs ağrısı, elektrokardiyografide (EKG) ST segment elevasyonu, T negatifliği ve kardiyak enzim düzeylerinde yükselmedir (6). Ani kardiyak ölüm görülen hastaların etiyolojisinde düşünülmelidir ve geniş vaka serilerinde hastane içi mortalite oranı \%3 olarak saptanmıştır $(7,8)$.

Her ne kadar anestezi indüksiyonu ile görülme sıklığının artabileceği söylense de literatürde bu hastaların anestezi yönetimi ile ilgili bildirilmiş vaka sayısı çok kısıtlıdır. Biz bu olgu sunumumuzda TKM hastasına anestezi yaklaşımımızı sunmayı amaçladık. 


\section{OLGU}

TKM tanısı almış, 19 yaşında 37 haftalık gebe acil sezeryan seksiyo (C/S) endikasyonu ile hastanemiz kadın hastalıkları ve doğum kliniğine kabul edildi. Hastanın preoperatif değerlendirmesinde, bir yıl önce acil servise bilinç kaybı nedeni ile başvurduğu ve gerçekleştirilen tetkikler sonucunda mayo klinik kriterlerine göre TKM tanısı konulduğu tespit edildi (9).

Operasyondan bir yıl önce yapılan EKG, ekokardiyografi (EKO) ve koroner anjiografi (KAG) raporlarl;

\section{KAG:}

- Sol ön inen arter (LAD) gövdeden pulmoner artere doğru fistül mevcut,

- $\quad$ Sirkümfleks (CX): Normal

- Sağ ana koroner arter (RCA): Normal

- Sol ventrikülografi: Apeks akinetik anevrizmatik ve bazal segmentler hiperkinetik

\section{EKO:}

- $\quad$ Ejeksiyon fraksiyonu (EF) \%20

- Bazal segmentler haricinde diğer tüm segmentler akinetik

- Sol ventrikül, ileri sistolik disfonksiyon

\section{EKG:}

- $\quad$ Sinüs ritmi

- Kalp hızı 75 atım/dakika,

- V1-6 T (-)

- Uzun QT

Hastanın taburculuk öncesi ventrikül fonksiyonlarının düzeldiği ve EF değerinin \%60 ile taburcu edildiği, hastane kayıtlardan öğrenildi. Taburculuktan bir yıl sonra acil olarak planlanan $\mathrm{C} / \mathrm{S}$ operasyonu öncesinde preoperatif yapılan ekokardiyografisinde EF \%60 olduğu görüldü. Mevcut bulgularla hasta ASA IIE olarak değerlendirilerek genel anestezi planlandı. Premedikasyon uygulanmayan hastaya, invaziv arter monitörizasyonu eklenerek rutin monitörizasyon uygulandı. Preoksijenasyon $\left(\% 100 \mathrm{O}_{2}\right.$ ile dört maksimal soluk) ardından sol el sırtından $20 \mathrm{G}$ kanül ile damar yolu açıldı ve laktatlı ringer çözeltisi başlandı. İndüksiyon ve intraoperatif dönemde hipotansiyon riski öngörülerek, efedrin ve intravenöz noradrenalin infüzyonu hazırlandı. Kardiyak disfonksiyonu anında tespit edebilmek amacıyla transtorasik ekokardiyografi hazırlığı yapıldı. Anestezi indüksiyonu verbal yanıt kaybolana kadar titre ederek toplam $2 \mathrm{mg} / \mathrm{kg}$ propofol ile gerçekleștirildi. Nöromusküler blok $1,2 \mathrm{mg} / \mathrm{kg}$ rokuronyum bromür ile sağlandıktan sonra krikoid bası uygulanarak hızlı seri entübasyon gerçekleştirildi ve operasyon başlatıldı. Anestezi idamesi \%50 hava-oksijen, 0,8-1 minimum alveolar konsantrasyon (MAK) sevofluran ile sağlandı. Bebeğin doğumu sonrası umblikal kordun klemplenmesinin ardından bölünmüș dozlarda toplam $1 \mathrm{mcg} / \mathrm{kg}$ fentanil intravenöz (iv) uygulandı. İntraoperatif dönem süresince herhangi bir aritmi gözlenmedi. Postoperatif analjezi amacıyla operasyon sonlanmadan yaklaşık 20 dakika önce $1 \mathrm{mg} / \mathrm{kg}$ tramadol ve 1 gr parasetamol iv uygulandı. Rezidüel blok $4 \mathrm{mg} /$ kg sugammadeks ile geri döndürüldü ve hastaya ekstübasyon öncesi 40 mg lidokain intravenöz uygulandıktan sonra ekstübasyon gerçekleştirildi. Postoperatif dönemde vital bulguları stabil seyreden hastanın derlenme ünitesindeki takibinde herhangi bir komplikasyon ile karşılaşılmadı ve servise gönderildi.

\section{Etik Beyan}

Çalışmanın yürütülmesi esnasında Helsinki Beyannamesi 2013, ICJM tavsiyeleri ile COPE'un Editör ve Yazarlar için Uluslararası Standartlarının yanısıra ilgili diğer biyoetik kılavuzlar dikkate alınmıştır.

\section{TARTIŞMA}

Hekimler uzun zamandır stres ve kardiyovasküler olaylar arasındaki olası ilişkinin farkındadır. Dote ve ark., 1991 yılında epikardiyal koroner arter stenozu olmaksızın akut başlangıçlı sol ventrikülün apikal ve orta bölümlerinin geçici geniş akinezisinin eşlik ettiğini bildirmişlerdir. Bu hastaların EKG si normal veya spesifik olmayan T dalgası anormalliği, prekordial ve ekstremite derivasyonları boyunca önemli ST elevasyonu gösterebilir (10). En sık görülen EKG bulgusu hafif ST segment yükselmesidir ve hastaların yaklaşık \%50-60'ında görülür. Tipik olarak semptomlar geçicidir ve anormal apikal duvar hareketleri günler veya haftalar içinde ortadan kalkar. Tüm bu kardiyak bulgulara rağmen, prognozu iyidir ve hastanede ölüm oranı \%0-8 arasındadır. Yaz aylarında, pazartesi ve sabah saatlerinde bu hastalığa ait belirtilerin daha sık olduğu ve bunun sebebinin katekolamin deşarjı, strese bağlı aşırı katekolamin salgılanması olarak açıklanmaya çalışılmıştır.

Ayırıcı tanıda akut MI, myokardit, aort diseksiyonu ve kalp tamponadı gibi morbidite ve mortalitesi yüksek olan kardiyak hastalıklar düşünülmelidir. Bu hastalıkların ayırı- 
cı tanısında acil anjiografi etkin bir yöntemdir. Anjiografide görülen sol ventrikül apikal balonlaşma ve koroner arterlerin normal olması TKM için tanısal değer taşır. Takatsubo kardiyomyopati tanısında en yaygın olarak Mayo klinik tanı kriterleri kullanılmakta ve özellikle kriterlerin hepsinin bulunması gerektiği belirtilmiştir (11).

\section{Mayo Klinik tanı ölçüitleri:}

1. Sol ventrikül apikal ve mid bölgelerinde ekokardiyografi veya ventrikülografi ile gösterilmiş, tek damarın anatomik yayılımı ile açıklanamayan geçici hipokinezi veya akinezi

2. Koroner anjiografi ile gösterilmiş anlamlı (>\%50) koronere arter darlığının olmaması

3. Elektrokardiyografide yeni saptanmış ST segmenti veya $\mathrm{T}$ dalga değişiklikleri

4. Kafa travması, intrakranial kanama, feokromasitoma, miyokardit veya hipertrofik kardiyomiyopati olmaması

Kardiyak hastalıklardan ayrı olarak, kesin tanı için feokromasitoma gibi katekolamin deşarjı yapan hastalıklar, kafa travması ve inme durumları dışlanmalıdır. Psikiyatrik hastalıklar, nöroleptik tedavi, sempatik sinir sistemi bozuklukları, kalp hızı değişkenliğinde azalma, trombosit fonksiyon değişiklikleri, proinflamatuar süreçlerde artış, kanser hastalarına radyoterapi ve kemoterapi uygulaması, ağrı krizleri, Alzheimer hastalığı TKM'ne yol açmaktadır.

Subaraknoid kanama ile TKM arasında açık ilişki olduğuna dair literatürde yayınlar mevcuttur. Üstelik bu durumun anestezinin komplikasyonları olabilen pulmoner ödem, uzamış entübasyon süresi ve serebral vazospazm ile ilişkili olduğu bildirilmiştir (12). Tüm bu komplikasyonlarla TKM birlikteliği, ekstübasyon sürecini mümkün mertebe sorunsuz geçebilmemiz için erken ekstübasyon ve sugammadeks kullanma ihtiyacı hissettirdi. Aksi taktirde uzun süre entübe halde tutmak, hastanın entübe halde ıkınması beraberinde ölümcül nörolojik komplikasyonlara yol açabilirdi. Bunlara ek olarak hastalarda kalp rüptürü, ventrikül ritm bozuklukları ve apikal trombüs gibi nadir fakat ölümcül komplikasyonlar gelişebilir ve bu durumda yoğun bakım takibi gerekmektedir. Biz de operasyona aldığımız olgumuz için preoperatif süreçte yoğun bakımda yerimizi ayırttık. Yoğun bakımda yakın ekokardiyografi ile takip yapılması gerektiğini ve bu durumların intraaortik balon pompası, antitrombotikler ve beta bloker kullanımıyla tedavi edilebileceği bilgisine sahiptik ve gerekli girişim ve farmakolojik hazırlıklarımızı yaptık. Farmakolojik olarak anjiyotensin dönüştürücü enzim inhibitörleri, anjiyotensin II Tip 1 reseptör blokerleri, spesifik aldosteron antagonisti (spironolakton) ve anksiyolitikler kullanılabilecek diğer te- davi ajanlarıdır. Ağrı varlığında opioid tedavisi tercih edilebilinir (13).

Literatürde anestezi yönetimi ile ilgili paylaşılan tecrübeler oldukça kısıtlıdır. Bizim olgumuzda sezaryen operasyonu için acil ameliyata alınan ve Takotsubo sendromu tanılı hastaya müdahalemizde genel anestezinin etkileri tartışılmaktadır. Bu olguda anestezi indüksiyonu sonrasında herhangi bir geçici sol ventrikül yetmezliğine rastlanmamıştır. TKM tanısı olan hastalarda sinüs ritmini korumak, taşikardi ve derin bradikardiden kaçınmak ve anestezi planını hastanın klinik tablosuna göre belirlemek gerekmektedir. Genel anestezinin nöroaksiyel anestezi yöntemlerine tercih edilmesi konusunda mevcut literatürler ışığında herhangi bir üstünlüğünü gösteren çalışma veya olgu serisi bulunmamaktadır. Olgumuzda anestezi yöntemini belirlerken rejyonel anestezi sezaryan operasyonu planlanan gebelerde klinik rutinimizde olmasına rağmen, hastanın hem acil olması hem de spinal anestezinin gebede intraabdominal basıncın yüksek olmasına bağlı, kardiyoakseleratör lifleri tutabileceği ve buna bağlı kalpte aynı anda gelişen hipokinezik bölgelerin etkisini arttırabileceğini, bununda ciddi komplikasyonlara yol açabileceğini için genel anestezi uygulamaya karar verdik. Genel anestezi için indüksiyonda iv propofolün kardiyodepresan etkisini en aza indirmek için yavaş ve titre ederek uyguladık. Küçükdurmaz ve ark., ikisinde genel anestezi birinde epidural anestezi uygulanan vakaların operasyon öncesi TKM sendrom tanısı olduğu bilinmeyen bir olgu serisinde, genel anestezi uygulanan hastalardan biri ölüm ile sonuçlanmıştır (14). Transüretral rezeksiyon-mesane tümörü (TUR-MT) operasyonu uygulanan TKM sendromlu hastada postoperatif birinci saatte ani olarak gelişen nefes darlığ 1 , taşikardi ve ST segment elevasyonu ve midapikal diskinezi tespit edildiği ve yapılan tetkikler sonucu hastanın Takatusubo kardiyomiyopatisi tanısı aldığı bildirilmiştir.

TKM'li hastaların çoğu akut koroner sendrom kliniği ile başvururlar ve \%3 oranında ani ölüm görülebilmektedir. Miyokardiyal fonksiyonları takip ederken normal tansiyonunu devam ettirmek için vazopressörler gerekebilir. Ayrıca artmış preload yetersiz sol ventrikül fonksiyonu olan hastalarda pulmoner ödeme neden olabileceği için hastaya göre optimize edilmelidir. Koroner arter hastalarından farklı olarak TC'li hastalarda diyastolik kan basıncının arttırılması miyokardiyal performansı iyileştirmez. İntrakranial anevrizma klemplenmesi amaciyla operasyona alınan TKM hastasında ekokardiyografi kılavuzluğunda ventrikül fonksiyonlarını değerlendirerek endotrakeal entübasyon işleminin gerçekleştirildiği raporlanmıştır. Başlangıçta transtorasik daha sonrasında ise transözefagial yöntem kullanılarak intraoperatif kardiyak durum, volüm ve hemodinamik yanıtı takip ettiklerini ve olaysız bir şekilde anevrizmanın klemplendiğini bildirmişlerdir. Ayrıca vazopressör ajan olarak hipotansiyon epizotlarında 0,05 
$\mathrm{mcg} / \mathrm{kg} / \mathrm{dk}$ hızında noradrenalin infüzyonu bașlamıșlardır. Levosimendan da kalsiyum duyarlaştırıcı ve potasyum kanal açıcı etkisi ile inotropik desteğin gerekli görüldüğü akut dekompanse kalp yetmezliği görülen TKM'li hastaların bașlangıç tedavisinde etkili seçenek olarak bulunmuștur (16). Olgumuz da gerekli vazopressör ajan hazırlığı yapmamıza rağmen, perioperatif süreç boyunca kullanmaya ihtiyaç duymadık. TKM öyküsü olan vakalarda kesin fayda sağladığı kanıtlanmamakla birlikte stres yanıtı baskılamak için opioidler, beta blokerler ve satral etkili alfa 2 agonist olan deksmededotimidin tercih edilebilir. Elektif vakalar intraoperatif ekokardiyografinin yapılabildiği ve intaaortik balon pompa kullanılabilecek kliniklerde gerçekleștirilmelidir. Biz kliniğimizde önerilen donanımların eşliğinde, olgumuzun genel anestezi altında herhangi bir hemodinamik kötüleşme görülmeden operasyonu gerçekleştirdik.

\section{SONUÇ}

Cerrahi müdahale gerektiren TKM hastalarında nüksü önlemek için, açıkça tanımlanmış bir anestezik-cerrahi strateji veya rehber henüz yoktur. Perioperatif dönemde muhtemel bir akut komplikasyonun erken teşhisi için mümkün olan en düşük uyarı ve sıkı takip en güvenli opsiyonlar gibi görünmektedir. Anestezi yöntemi ile ilgili net bir görüș olmamasına rağmen, hedef hastaların perioperatif süreçte en optimal kardiyak koşullara sahip olması, taşikardi, bradikardi ve preload değişikliklerinden kaçınmak olmalıdır. Genel anestezi uygulanacaksa, entübasyon ve ekstübasyon esnasında, katekolamin artışına neden olacak durumların en aza indirgenmesi gerekmektedir. Elektif şartlarda operasyon hazırlığının tam yapılması ve postoperatif takip amaçlı yoğun bakımın hazır olması gerektiğidir.

\section{KAYNAKLAR}

1. Sato H, Tateishi H, Dote K, Uchida T, Ishihara M. Tako-tsubo-like left ventricular dysfunction due to multivessel coronary spasm. In: Kodama K, Haze K, Hori M, editors. Clinicalaspect of myocardial injury: from ischemia to heart failure. Tokyo: Kagakuhyoronsha Publishing Co.; 1990.p.56-64.

2. Kurisu S, Kihara Y. Tako-tsubo cardiomyopathy: clinical presentation and underlying mechanism. J Cardiol 2012;60:429-37.

3. Bybee KA, Prasad A, Barsness G, Wright RS, Rihal CS, Clinical characteristics, outcomes, and impaired myocardial microcirculation in patients with transient left ventricular apical ballooning syndrome: a case-series from a U.S. medial center. Am J Cardiol. 2004;94:343-46

4. Mrdovic I, Kostic J, Perunicic J, Asanin M, Vasiljevic Z, Ostojic M. Right ventricular takotsubo cardiomyopathy. J Am Coll Cardiol 2010;55:1751.
5. Win CM, Pathak A, GuglinM. Not takotsubo: a different form of stress induced cardiomyopathy: a case series. Congest Heart Fail 2011;17:38-41

6. Kurisu S, Kihara Y. Clinical management of takotsubo cardiomyopathy. Circ J. 2014;78:1559-66.

7. Akashi YJ, Goldstein DS, Barbaro G, Ueyama T. Takotsubo cardiomyopathy: a new form of acute, reversible heart failure. Circulation. 2008;118:2754-62.

8. Elesber AA, Prasad A, Lennon RJ, Wright RS, Lerman A, Rihal CS. Four-year recurrence rate and prognosis of the apical ballooning syndrome. Journal of the American College of Cardiology 2007;50(5):448-52

9. Madhavan M, Prasad A. Proposed Mayo Clinic criteria for the diagnosis of Tako-Tsubo cardiomyopathy and long-term prognosis. Herz. 2010;35:240-3.

10. Dote K, Sato H, Tateishi H, Uchida T, Ishihara M. Myocardial stunning due to simultaneous multivessel coronary spasms: a review of 5 cases. J Cardiol 21: 203-214, 1991 (in Japanese).

11. Gültekin N, Dalgıç Y. Tako-Tsubo Kardiyomiyopatisi Tako- Tsubo Cardiomyopathy Kardiyoloji AD, İstanbul Üniversitesi Kardiyoloji Enstitüsü, İstanbul Turkiye Klinikleri J Cardiol-Special Topics 2016;9:1-7

12. LeeVH, Connolly HM, Fulgham JR, Manno EM, Brown RD Jr, Wijdicks EF. Tako-tsubo cardiomyopathy in aneurysmal subarachnoid hemorrhage: an under appreciated ventricular dysfunction. J Neurosurg. 2006;105:264-70.

13. Singh SB, Harle IA. Takotsubo cardiomyopathy secondary in part to cancer-related pain crisis: a case report. J Pain Symptom Manage. 2014;48:137-42.

14. Küçükdurmaz Z, Karapınar H, Oflaz MB, Gül İ, Aydın G, Güneş H, et al. Takotsubo kardiyomiyopatisi hakkında klinik deneyimimiz ve ülkemizden bildirilen ilk olgu serisi Türk Kardiyol Dern Arş - Arch Turk Soc Cardiol 2013;41:212-17.

15. Deniz S, Bakal Ö, İnangil G, Şen H, Özkan S. Postoperatif Evrede Gelişen Bir Takatusubo Kardiyomiyopatisi Period Turk J Anaesth Reanim 2015; 43: 47-9

16. Santoro F, Ieva R, Ferraretti A, Ienco V, Carpagnano G, Lodispoto $\mathrm{M}$, et al. Safety and feasibility of levosimendan administration in takotsubo cardiomyopathy: A case series. Cardiovasc Ther 2013;31:133-7. 